\title{
Ineffectiveness of capsule endoscopy and total double-balloon enteroscopy to elicit the cause of obscure overt gastrointestinal bleeding: think GIST!
}

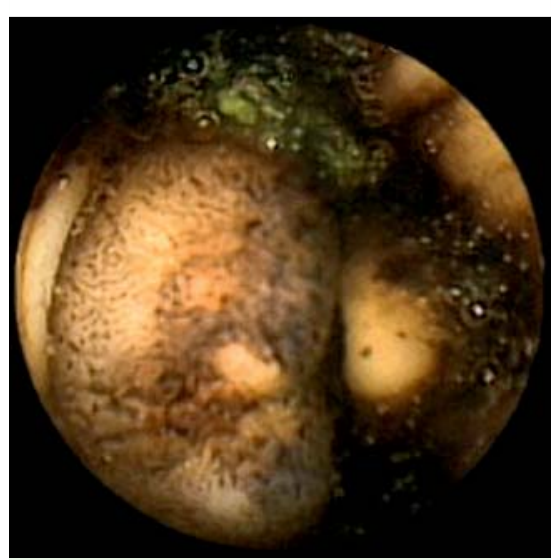

Fig. 1 Submucosal jejunal protuberance in patient with active bleeding.

A 55-year-old healthy woman was admitted because of a 2-month history of recurrent melena. Two previous esophagogastroduodenoscopies (EGD) and colonoscopies were negative. On admission the patient was hemodynamically stable. Her hemoglobin concentration was $8.6 \mathrm{~g} / \mathrm{dL}$. Physical examination was unremarkable. An emergency repeat EGD was negative. Capsule endoscopy revealed fresh blood, a suspicious submucosal lesion but no mucosal erosions in the jejunum ( $\bullet$ Fig. 1 ). Emergency next-day double-balloon enteroscopy (DBE) (oral and anal) did not show any blood or luminal lesion. Multislice computed tomographic (MSCT) angiography revealed a tumor attached externally to the distal jejunum ( $\bullet$ Fig. 2 ).

The patient underwent surgery and the tumor was completely resected ( Fig. 3 ). Histopathological examination showed a gastrointestinal stromal tumor (GIST).

This case is interesting for several reasons. First, it shows the utility of small-bowel endoscopy to discover active bleeding. Second, it demonstrates that radiological methods such as CT angiography should be included in the algorithm for acute overt gastrointestinal bleeding [1]. In this case, capsule endoscopy showed active gastrointestinal bleeding, but it was unable to define any mucosal lesion. One would expect that DBE, with its capability of to-and-fro movements and ability to

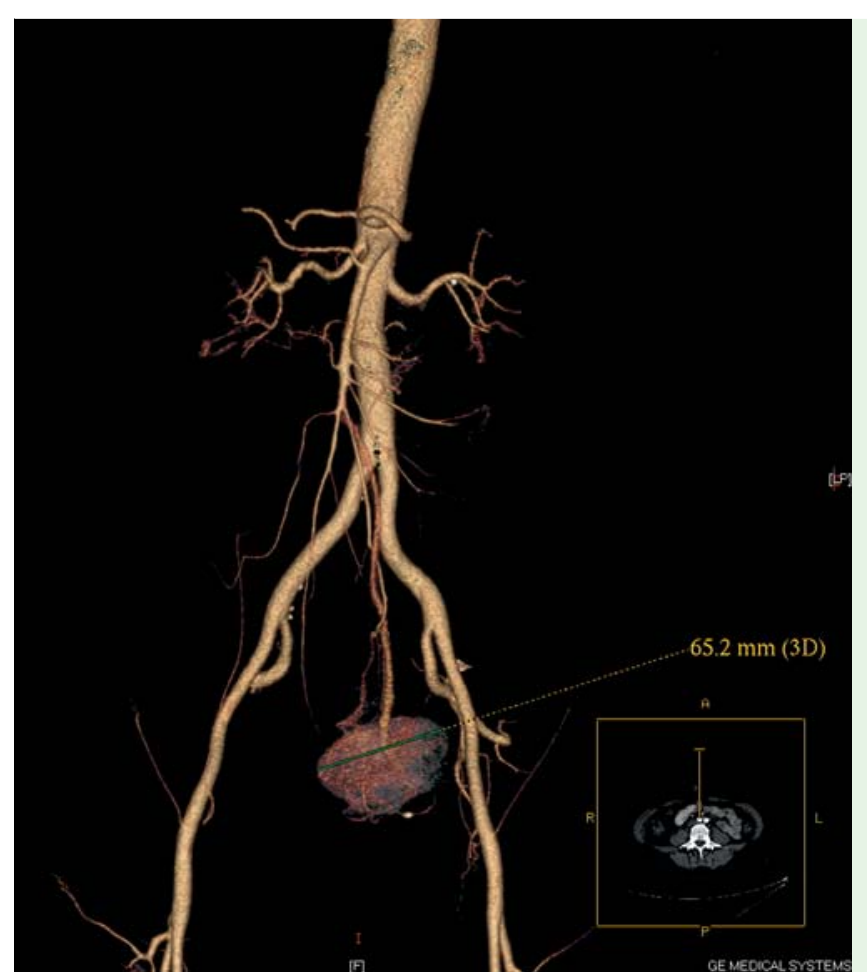

Fig. 2 Reconstructed CT angiographic image shows a tumor attached externally to the small bowel at the level of the distal jejunum with well-defined margins and a prominent feeding artery.

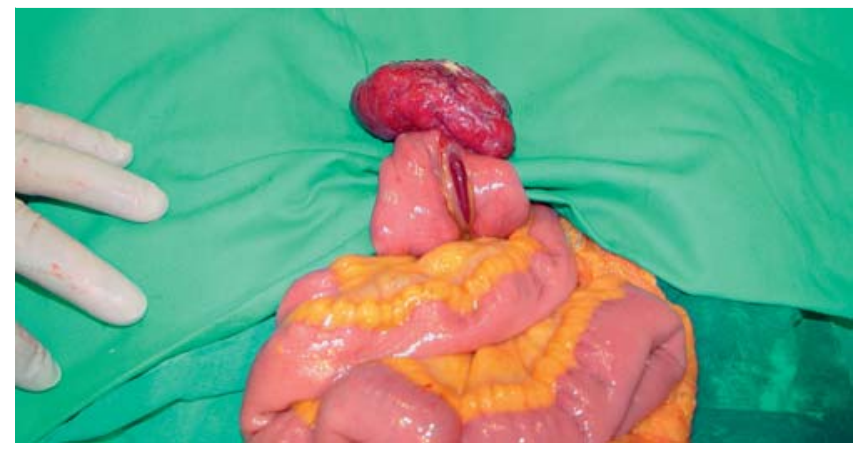

Fig. 3 Surgical (in situ) specimen showing a large exophytic solid tumor of the jejunum with a large vessel coursing at its apex.

flush the mucosa with water, would allow better mucosal inspection [2]. However, the subtle submucosal localization of this GIST made endoscopic diagnosis impossible $[3,4]$. The tumor mass was mainly located outside the lumen and appeared as a huge peduncle attached to the small bowel. Thus, in this case, only CT, MRI, angiography, or an exploratory laparotomy would help the clinician reach a diagnosis. In summary, in the era of advanced luminal small-bowel imaging this case reminds us of the challenging pathological appearance of GIST and the necessity of including radiological imaging methods in the management algorithm of patients with acute obscure overt gastrointestinal bleeding in whom endoscopic methods do not permit a diagnosis.

\section{Acknowledgement \\ $\nabla$}

Ivan Jovanovic, $\mathrm{MD}, \mathrm{PhD}$ is a recipient of the ASGE Cook Don Wilson Award 2010. This work was performed during his award period. 


\section{Endoscopy_UCTN_Code_CCL_1AC_2AC}

\section{Competing interests: None}

\section{Jovanovic ${ }^{1}$, Z. Krivokapic ${ }^{2}$, N. Menko-} vic $^{3}$, M. Krstic ${ }^{1}$, K. Mönkemüller ${ }^{4}$

1 Clinic for Gastroenterology and Hepatology, Clinical Center of Serbia, Belgrade, Serbia

2 First Surgical Clinic, Clinical Center of Serbia, Belgrade, Serbia

3 Institute for Radiology, Clinical Center of Serbia, Belgrade, Serbia

4 Department of Internal Medicine and Gastroenterology, Marienhospital, Bottrop, Germany

\section{References}

1 Fry LC, Neumann H, Kuester D et al. Small bowel polyps and tumours: endoscopic detection and treatment by double-balloon enteroscopy. Aliment Pharmacol Ther 2009; 29: 135-142

2 Mönkemüller K, Neumann $H$, Meyer $F$ et al. A retrospective analysis of emergency double balloon enteroscopy for small bowel bleeding. Endoscopy 2009; 41: 715-717

3 Nowain A, Bhakta H, Pais S et al. Gastrointestinal stromal tumors: clinical profile, pathogenesis, treatment strategies and prognosis. J Gastroenterol Hepatol 2005; 20: 818-824

4 Fang SH, Dong DJ, Zhang SZ, Jin M. Angiographic findings of gastrointestinal stromal tumor. World J Gastroenterol 2004; 10: $2905-2907$
Bibliography

DOI $10.1055 / \mathrm{s}-0030-1256004$

Endoscopy 2011; 43: E91 - E92

(c) Georg Thieme Verlag KG Stuttgart · New York . ISSN 0013-726X

\section{Corresponding author} Ivan Jovanovic, MD, PhD

Clinic for Gastroenterology and Hepatology Clinical Center of Serbia, Belgrade

Koste Todorovica 2,

11000 Beograd

Serbia

Fax: +381-11-3615587

ivangastro@beotel.rs 